\title{
DINÂMICA POPULACIONAL E INCIDÊNCIA DE MOSCAS-DAS-FRUTAS E PARASITOIDES EM CULTIVARES DE PESSEGUEIROS (Prunus persica L. BATSCH) NO MUNICÍPIO DE PRESIDENTE PRUDENTE-SP ${ }^{1}$
}

\author{
SÔNIA MARIA NALESSO MARANGONI MONTES ${ }^{2}$, ADALTON RAGA ${ }^{3}$, \\ APARECIDA CONCEIÇÃO BOLIANI ${ }^{4}$, PEDRO CÉSAR DOS SANTOS ${ }^{4}$
}

RESUMO - Esta pesquisa teve como objetivos avaliar a dinâmica populacional e registrar a diversidade de moscas-das-frutas (Diptera: Tephritoidea) em cultivares de pessegueiro Tropical, Talismã, Aurora 2, Aurora 1, Dourado 2 e Doçura 2, enxertadas sobre os porta-enxertos 'Okinawa' e Umê, em Presidente Prudente-SP. Foram realizadas as correlações da dinâmica populacional com a temperatura e a precipitação, e também a infestação com as características químicas dos frutos, Sólidos Solúveis e Acidez Titulável. No período de julho de 2004 a dezembro de 2006, a dinâmica populacional de moscas-das-frutas foi obtida através de coletas semanais de moscas-das-frutas em armadilhas McPhail, e a incidência foi determinada através da coleta de 30 frutos/planta/cultivar. O delineamento estatístico adotado foi o inteiramente casualizado, com cinco repetições. Ceratitis capitata foi predominante nas cultivares de pessegueiros estudadas. Não foi observada correlação significativa entre população de moscas-das-frutas e as variáveis de temperatura e precipitação, e sólidos solúveis e ácidez titulável. Entre as cultivares de pêssego, Aurora 2 apresentou maior infestação por C. capitata, da ordem de 22 e $23 \%$ nos anos 2004 e 2006, respectivamente. Também foi registrada a incidência de Neosilba spp. em frutos de pêssego. Doryctobracon areolatus (Braconidae), Tetrastichus giffardianus (Eulophidae) e Pachycrepoideus vindemmiae (Pteromalidae) foram recuperados de pupários de Tephritidae.

Termos para indexação: pêssego, porta-enxerto, dinâmica populacional, Tephritidae, Lonchaeidae.

\section{POPULATION DYNAMIC AND OCCURRENCE OF FRUIT FLIES AND THEIR PARASITOIDS IN PEACH CULTIVARS (Prunus persica L. BATSCH) IN PRESIDENTE PRUDENTE MUNICIPALITY, SP}

\begin{abstract}
The objectives of this research were evaluate the population dynamic and diversity of fruit flies (Diptera: Tephritoidea) on peach cultivars Tropical, Talisma, Aurora 2, Aurora 1, Dourado 2 and Doçura 2, under the rootstocks 'Okinawa' and Umê, in Presidente Prudente, São Paulo, Brazil. The dynamic population of fruit flies was correlated with temperature and precipitation. The fruit fly infestation was correlated with chemical characteristics of fruits. During July 2004 to December 2006, the fruit fly population was monitored weekly using McPhail traps. The natural infestation was estimated from 30 fruits of each cultivar collected per year. The experiment was conducted under randomized design with five replications. Ceratitis capitata was dominant on peach cultivars for the both rootstocks. No significant correlations were detected between the fruit fly densities and the temperature and precipitation, and the variables soluble solids and titratable acidity. Among peach cultivars, Aurora 2 presented the highest infestation by C. capitata, reaching $22 \%$ and 23\%, in 2004 and 2006, respectively. Neosilba spp. (Lonchaeidae) was also recovered from peaches. Doryctobracon areolatus (Braconidae), Tetrastichus giffardianus (Eulophidae) and Pachycrepoideus vindemmiae (Pteromalidae) were recovered from Tephritidae pulparium.
\end{abstract}

Index-terms: peach, rootstocks, population dynamic, Tephritidae, Lonchaeidae.

\footnotetext{
'(Trabalho 086-10). Recebido em: 29-3-2010. Aceito para publicação em: 01-12-2010. Parte da tese do primeiro autor, apresentado à FEIS/UNESP para obtenção do Título de Doutor. Auxílio à pesquisa da FAPESP (Processo nº5/55649-5).

${ }^{2}$ Eng.Agr., Dr. Pesquisador Científico da APTA-Pólo Regional Alta Sorocabana Rodovia Raposo Tavares, km561 C.P. 298, Presidente Prudente-SP, CEP 19015-970. E-mail: soniamontes@apta.sp.gov.br

${ }^{3}$ Eng.Agr., Dr. Pesquisador Científico do Centro Experimental do Instituto Biológico. Rodovia Heitor Penteado C.P. 70, Campinas-SP, CEP- 13001-970 . E-mail adalton@biologico.sp.gov.br

${ }^{4}$ Eng.Agr., Prof.Dr., FEIS/UNESP. Av. Brasil, 56 Ilha Solteira-SP, CEP 15.385-000. E-mails: boliani@agr.feis.unesp.br; santospc@agr.feis.unesp.br
} 


\section{INTRODUÇÃO}

As moscas-das-frutas compõem um complexo de mais de 5.000 espécies pertencentes à Família Tephritidae distribuídas por todas as regiões da Terra. Aproximadamente 20 espécies são responsáveis por enormes perdas na produção e, provavelmente, são as pragas mais destrutivas de frutos em todo o mundo (MARTINS, 2002).

Ceratitis capitata (Wied.) e sete espécies de Anastrepha (A. grandis Macquart, A. fraterculus (Wied.), A. obliqua (Macquart), A. pseudoparalella (Loew), A. sororcula Zucchi, A. striata Schiner e $A$. zenildae Zucchi) são as moscas-das-frutas mais importantes do ponto de vista econômico para o Brasil (ZUCCHI, 2000a).

A mosca-do-mediterrâneo (C. capitata) é responsável pelos maiores danos à fruticultura por se encontrar distribuída em praticamente todo o mundo, atacando 18 hospedeiros comerciais e utilizando mais de 200 outros hospedeiros alternativos (NASCIMENTO; CARVALHO, 2000; ZUCCHI, 2000b). No Estado de São Paulo, a ocorrência de $C$. capitata está preferencialmente relacionada a hospedeiros introduzidos, como pêssego, pera, caqui, café e outros (MALAVASI et al., 2000), e sua dispersão em áreas urbanas deve estar ocorrendo devido ao plantio de chapéu-de-sol Terminalia catappa L. (SOUZA FILHO, 2006).

A mosca-do-mediterrâneo é uma espécie multivoltina, isto é, desenvolve várias gerações/ano e, além disso, as populações dessa espécie podem ocorrer o ano todo, em razão da sucessão de hospedeiros e da capacidade de desenvolver-se em uma grande diversidade de frutos hospedeiros. As populações de C. capitata passam de uma espécie de frutífera para outra, conforme as épocas do ano, como, por exemplo, migrar de cafezal para cultivares tardias de citros (ZUCCHI, 2000B; RAGA et al., 2002). O dano de moscas-das-frutas, em frutos como o pêssego, pode não ser perceptível, pois inicialmente o aspecto visual externo do fruto permanece inalterado. Todavia, ao se apalpar o fruto, nota-se a perda de consistência e resistência (SALLES, 1998).

A região do oeste do Estado de São Paulo apresenta excelentes características de clima e solo para o desenvolvimento da fruticultura, inclusive para a produção de pêssegos de qualidade (MONTES et al., 2008). Entretanto, existe naquela região uma ausência de estudos sobre a ocorrência de moscas-das-frutas em pomar de pêssego. No presente experimento, objetivou-se determinar a dinâmica populacional e identificar as espécies de Tephritoi- dea, analisar a ocorrência temporal e sua correlação com dados de clima, e as características químicas dos frutos de cultivares de pêssego na região de Presidente Prudente-SP.

\section{MATERIAL E MÉTODOS}

O experimento foi conduzido no período de julho de 2004 a dezembro de 2006, em pomar de pessegueiro instalado no Polo Regional da Alta Sorocabana-APTA, Presidente Prudente-SP (UTM $7545288,76 \mathrm{~m} \mathrm{~N}, 459930,31 \mathrm{~m}$ E e altitude 424,29 m). O pomar continha as cultivares Dourado 2, Doçura 2, Tropical, Talismã, Aurora 2 e Aurora 1. No início do experimento, o pomar de pêssego tinha cinco anos de idade e apresentava espaçamento de $6,0 \times 3,0 \mathrm{~m}$ para o porta-enxerto Okinawa e de 6,0 x 1,5 m para Umê.

Os tratos culturais realizados no pomar de pêssego foram os convencionais indicados para cultura (PEREIRA et al., 2002), tais como: superação da dormência artificial realizada com Cianamida hidrogenada $(0,5 \%)+$ óleo mineral $(1 \%)$, raleio de frutos, adubações, controle de plantas espontâneas (glifosato a $0,5 \%$ de i.a.), podas verde e seca, e irrigação por microaspersão.

Para a determinação da flutuação populacional de adultos de Tephritidae, no período de julho/2004 a dezembro/2006, foram mantidas, no interior do pomar de pêssego, três armadilhas McPhail de base amarela, instaladas na altura de 1,50 $\mathrm{m}$ do solo e no interior da copa da planta. Em cada armadilha, utilizaram-se como atrativo alimentar 400 $\mathrm{mL}$ de solução de proteína hidrolizada marca Isca Mosca, diluída em água a 5\% v/v. Semanalmente, foram realizadas as coletas e o reabastecimento das armadilhas. O conteúdo das armadilhas era transportado ao Laboratório de Qualidade e Sanidade Vegetal do Polo Alta Sorocabana-SP, para proceder à triagem dos tefritídeos coletados.

Os resultados da flutuação populacional de adultos de Tephritidae foram correlacionados com as variáveis climáticas, utilizando-se do Programa Estatístico SAS, determinando o coeficiente de correlação de Pearson, com nível de significância de 5\%. Os dados de precipitação pluviométrica e temperatura (Figura 1) foram obtidos da Estação Meteorológica da FCT/UNESP de Presidente Prudente-SP, distante a 4,5 km do pomar de pêssego.

Para a avaliação da incidência de moscasdas-frutas em pêssegos, foram coletados anualmente 30 frutos no ponto de colheita por planta, em cinco plantas de cada uma das seis cultivares e em cada porta-enxerto (Okinawa e Umê). Os frutos colhidos eram imediatamente transportados ao laboratório, 
onde eram pesados e acondicionados individualmente em potes plásticos descartáveis, com capacidade para $500 \mathrm{~mL}$, contendo uma mistura de areia + vermiculita até $1 / 3$ do seu volume. Os potes eram cobertos com tecido tipo voal, preso por elásticos de látex, e foram mantidos em laboratório por aproximadamente 30 dias, em condições de temperatura e umidade ambiente. Os espécimes de Tephritoidea foram contados, sexados, fixados em álcool a $70 \%$ e mantidos em frascos devidamente etiquetados para posterior identificação.

\section{RESULTADOS E DISCUSSÃO}

\section{Dinâmica populacional das moscas-das-frutas e influência de condições climáticas}

Observou-se a predominância de C. capitata em armadilhas (Figuras 2 e 3), com captura de 308 espécimes da mosca-do-mediterrâneo, no período de julho a dezembro de 2004, sendo 76,95\% de fêmeas e $23,05 \%$ de machos. De janeiro a novembro de 2006 , foram capturados 916 espécimes, sendo $60,37 \%$ de fêmeas e $39,63 \%$ de machos.

Também foram coletados em armadilhas 28 espécimes de Anastrepha, sendo sete espécimes em 2004, uma em 2005 e vinte em 2006, sendo identificadas A. barbiellinii (Lima), A. montei (Lima), A. pickeli (Lima) e A. pseudoparallela (Loew).

No ano de 2005, não houve registro da ocorrência de $C$. capitata, tanto em armadilhas quanto em frutos, provavelmente devido à alta incidência de ferrugem do pessegueiro Tranzschelia discolor (Fuckel) Tranzschel \& M.A. Litv, que ocasionou queda precoce de folhas, com reflexos na produção quantitativa de frutos.

Mesmo havendo disponibilidade hospedeira, a ocorrência de Anastrepha spp. é baixa em relação à $C$. capitata, apontando preferência de $C$. capitata pelo pêssego também nesta região, como citado por Malavasi et al. (2000). Considerando a preferência hospedeira de $C$. capitata por café e pêssego (SOUZA FILHO, 1999; RAGA et al., 2002), é possível inferir que a dominância de $C$. capitata tenha sido proporcionada pelo final da maturação de frutos e colheita de café nos arredores de Presidente Prudente, e do próprio experimento. Entretanto, mesmo em regiões tropicais, C. capitata tem ocorrido com maior frequência em espécies frutíferas comerciais introduzidas (SOUZA FILHO, 1999; MALAVASI et al., 1980; AGUIAR-MENEZES; MENEZES, 1996).

$\mathrm{Na}$ análise faunística da população de moscasdas-frutas em pomares de goiaba, laranja-doce e pomares caseiros diversificados, da região noroeste do Rio de Janeiro, Ferrara et al. (2004) observaram predominância de $C$. capitata e A. fraterculus.

Garcia et al. (2003a; 2003b) obtiveram maior incidência de $A$. fraterculus nos meses de dezembro e janeiro, concomitante com o período de frutificação do pessegueiro, com predominância de $A$. fraterculus na região oeste de Santa Catarina, tendo havido ocorrência acidental de C. capitata.

A maior infestação de pêssegos por Anastrepha spp. na região leste do Estado de São Paulo, segundo Souza Filho (2006), deve-se à competição interespecífica, onde possivelmente a abundância dos indivíduos de Anastrepha spp. provoque ataque aos de C. capitata na superfície do fruto, fato não observado no presente estudo, em função da baixa ocorrência de Anastrepha spp. no pomar estudado.

Registrou-se pico populacional em outubro e novembro/2004, e setembro e outubro/2006 (média de $22^{\circ}$ a $26^{\circ} \mathrm{C}$ e precipitação total de $507,6 \mathrm{~mm}$ em 2004; média de 22,5 a $26,5^{\circ} \mathrm{C}$ e precipitação total de $615,1 \mathrm{~mm}$ em 2006) (Figura 1), onde provavelmente a população de $C$. capitata, atraída pela frutificação do pêssego, migrou de uma área experimental de um (01) ha de cafeeiro que se encontra a uma distância aproximada de $60 \mathrm{~m}$ da área do presente estudo. Segundo Raga et al. (2002), aproximadamente 70\% dos adultos de moscas-das-frutas obtidos de frutos de café do Estado de São Paulo pertencem a C. capitata. $\mathrm{O}$ índice MAD atingiu valor máximo de 3,71 moscas/armadilha/dia em 24-11-2004 e 11,14 moscas/ armadilha/dia em 20-09-2006 (Figuras 3 e 4).

Não houve correlação significativa entre a população de $C$. capitata e as variáveis temperatura e precipitação (Tabela 1). Este fato pode indicar que a incidência de moscas-das-frutas, avaliada no presente estudo, esteve mais em função da disponibilidade de hospedeiros e estágio de maturação dos frutos do que a fatores climáticos. Para Puzzi e Orlando (1965), os fatores bióticos (hospedeiros e estágio de maturação dos frutos) são mais importantes na densidade populacional que os fatores abióticos (temperatura, umidade relativa e precipitação pluviométrica). O comportamento das moscas é muito variável com respeito aos parâmetros meteorológicos, principalmente o local e o ano, bem como a espécie hospedeira e o período de maturação dos frutos (SOUZA FILHO et al., 2000).

Parra et al. (1982) observaram correlação positiva das populações de C. capitata com a temperatura e negativamente com a umidade relativa, quando esses dados foram tomados microclimaticamente. No Rio Grande do Sul, Silva et al. (2004) avaliaram a população de Anastrepha spp. e C. capitata em pomares de citros, associando temperaturas mais 
elevadas e ocorrência de chuvas, com o aumento populacional das moscas-das-frutas.

\section{Infestação dos frutos por moscas-das-frutas}

Na avaliação da infestação de moscas-dasfrutas em pêssegos, em 2004, emergiram 1.601 exemplares de C. capitata, oriundos da coleta de 429 frutos das seis cultivares, sendo $18,80 \%$ de machos e $81,20 \%$ de fêmeas. Em 2006, foram avaliados 1.620 frutos, originando a emergência de 3.078 indivíduos de $C$. capitata, sendo $49,58 \%$ de machos e $50,42 \%$ de fêmeas.

Com relação à infestação de moscas-das-frutas em 2004, em ambos os porta-enxertos avaliados, as cultivares apresentaram variação de infestação por moscas-das-frutas, com média de $55 \%$. Não se observou diferença estatística na infestação das diferentes cultivares sobre 'Okinawa', contudo a cv. Aurora-2 sobre o porta-enxerto Umê apresentou $100 \%$ de frutos infestados, diferindo estatisticamente das demais (Tabela 2).

O número médio de moscas/fruto no ano de 2004 foi de 2,05 para cultivares sobre 'Okinawa' e 2,22 sobre Umê, não havendo diferença estatística entre as cultivares de mesmo porta-enxerto (Tabela 2). Com relação à infestação de moscas-das-frutas em 2006, observou-se não haver diferença estatística na infestação das diferentes cultivares sobre os dois porta-enxertos avaliados (Tabela 3 ). O número médio de moscas/fruto foi de 1,63 para cultivares sobre 'Okinawa' e 1,78 sobre Umê, não havendo diferença estatística entre as cultivares. Em relação à infestação dos frutos, para os dois porta-enxertos avaliados, foi da ordem de $32-34 \%$, inferior ao ano de 2004.

Dos frutos coletados em 2006, as percentagens médias de infestação das cultivares sobre 'Okinawa' e Umê (Tabela 3 ) foram, respectivamente, de $62,54 \%$ e $58,85 \%$ de C. capitata,e $17,38 \%$ e $11,09 \%$ de Neosilba spp. (Lonchaeidae). Com relação à infestação por lonqueídeos, as cultivares não diferiram entre si; entretanto, observa-se maior percentagem nas cultivares Aurora 2, Talismã e Doçura 2 (Tabela 3). Espécies de Neosilba podem tornar-se pragas de pêssegos na região oeste do Estado de São Paulo, como ocorre com frutos cítricos no Estado do Mato Grosso do Sul (UCHÔA et al., 2002). Em Monte Alegre do Sul (SP), Souza-Filho et al. (2009) registraram em pêssegos a infestação por Neosilba certa (Walker), N. pendula (Bezzi) e N. zadolicha McAlpine \& Steyskal.

Souza Filho (2006), em Monte Alegre do Sul (SP), verificou picos elevados e bem superiores de C. capitata em relação à Anastrepha sp., durante o período de frutificação de pessegueiros, nos anos de 2003 e 2004; entretanto, a taxa de frutos infestados com Anastrepha spp. foi superior àquela com frutos infestados por $C$. capitata, resultado diferente do presente estudo, fato que demonstra a variação da diversidade de moscas-das-frutas de acordo com a região produtora.

Dos pupários de moscas obtidos no presente estudo, houve a emergência dos seguintes Hymenoptera parasitoides: Doryctobracon areolatus Szépligeti (Braconidae), Tetrastichus giffardianus Silvestri (Eulophidae), Pachycrepoideus vindemmiae Rondani (Pteromalidae) e espécies de Diapriidae, exercendo controle biológico das moscas-das-frutas em Presidente Prudente-SP.

Souza Filho et al. (2009) relataram maior taxa de parasitismo por braconídeos em períodos onde houve maior infestação de Anastrepha spp., além de não ter registrado a emergência de parasitoides em C. capitata. Costa et al. (2005) registraram, no Nordeste brasileiro, o parasitoide $T$. giffardianus, introduzido em 1937 pelo Instituto Biológico no Estado de São Paulo, para controle biológico de C. capitata. Contudo, a redescoberta de T. giffardianus no presente estudo aponta a possibilidade de controle biológico de moscas-das-frutas com a utilização dessa espécie de parasitoide no Brasil.

\section{Influência das características químicas na infestação de moscas-das-frutas nos frutos}

A análise de correlação de Pearson dos sólidos solúveis (SS) e acidez titulável (AT), nas cultivares versus infestação de moscas em frutos e o número de moscas por fruto, não demonstrou correlação significativa para ambos os porta-enxertos avaliados no ano de 2006 (Tabela 4). Este fato pode indicar que os teores de SS e AT não afetam a infestação e o número de $C$. capitata/fruto. Provavelmente, outros fatores bióticos estejam envolvidos na preferência por oviposição e na biologia da mosca-do-mediterrâneo.

Segundo Souza Filho (2006), frutos de pêssego com aproximadamente $2,0 \mathrm{~cm}$ de diâmetro podem ser infestados por Anastrepha spp. e C. capitata. O autor observou não haver correlação significativa da acidez e pH de três cultivares de pessegueiros em relação às infestações das moscas-das-frutas. Entretanto, existe correlação positiva da firmeza, tamanho e coloração dos frutos de todas as cultivares analisadas. Desta forma, a suscetibilidade do pêssego ao ataque pode ser mais bem diagnosticada pelos parâmetros físicos. 
Temperatura $\multimap$ Precipitação $(\mathrm{mm})$

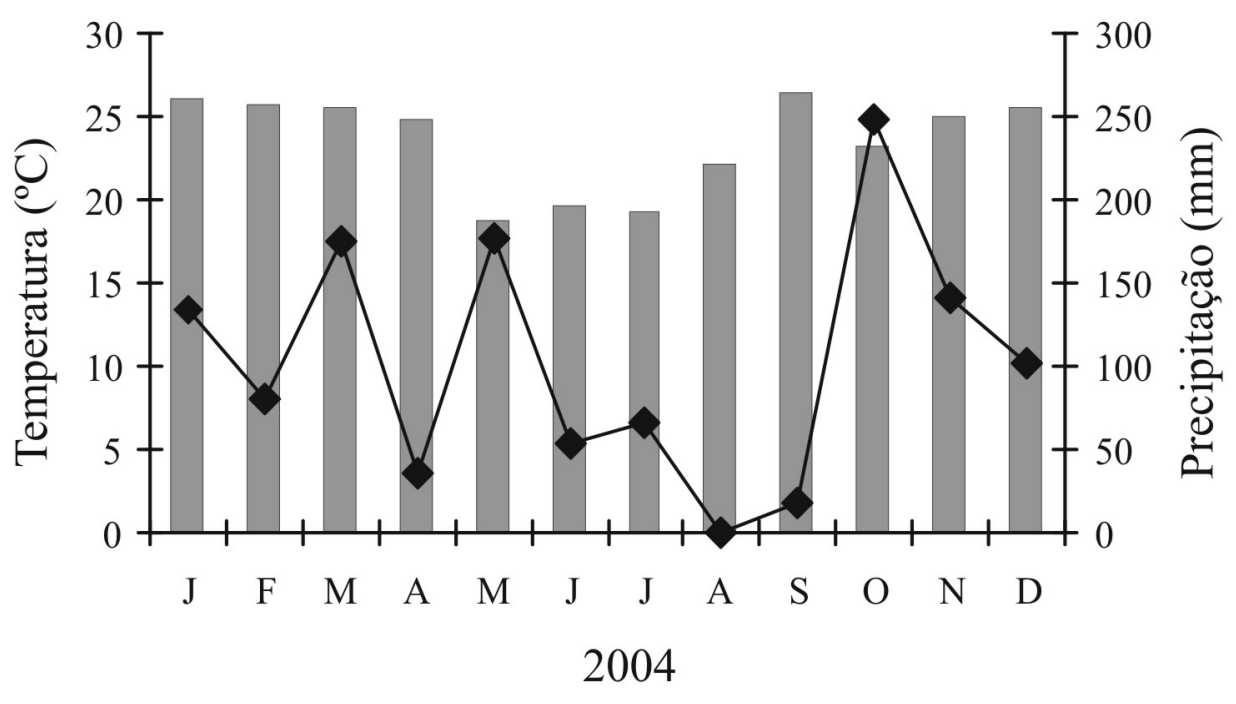

$\square$ Temperatura $\longrightarrow$ Precipitação $(\mathrm{mm})$

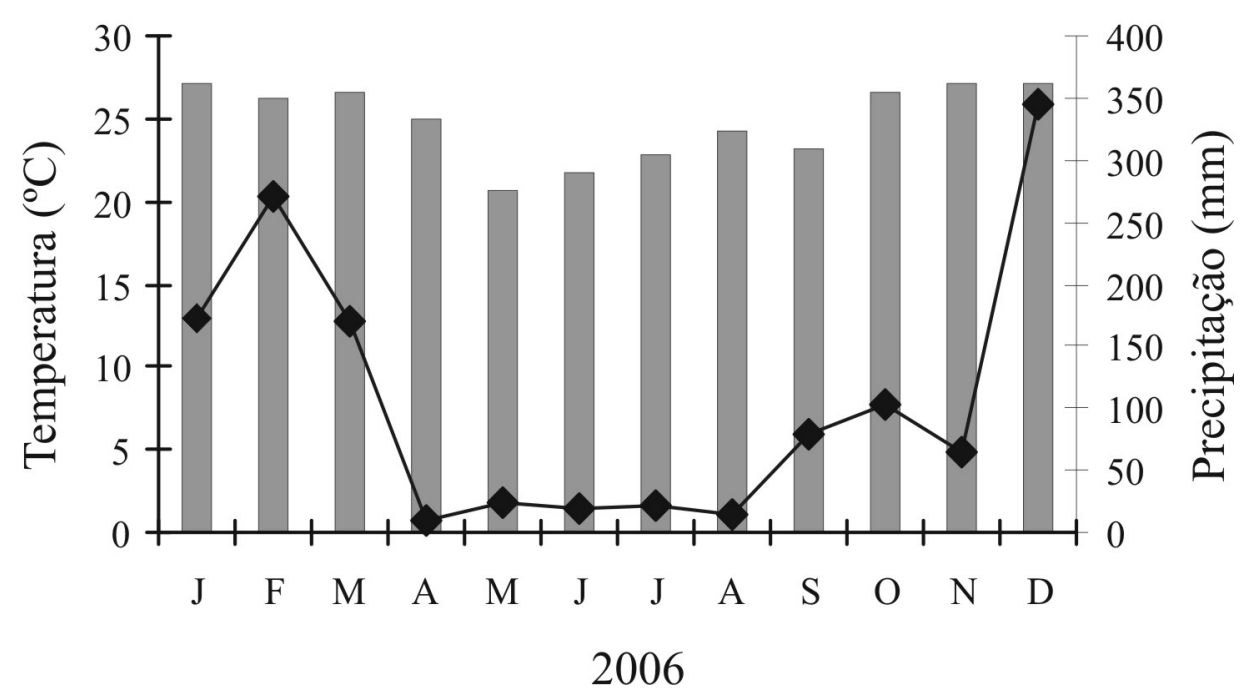

FIGURA 1 - Dados mensais de precipitação e temperatura média de Presidente Prudente-SP, nos anos de 2004 e 2006. 


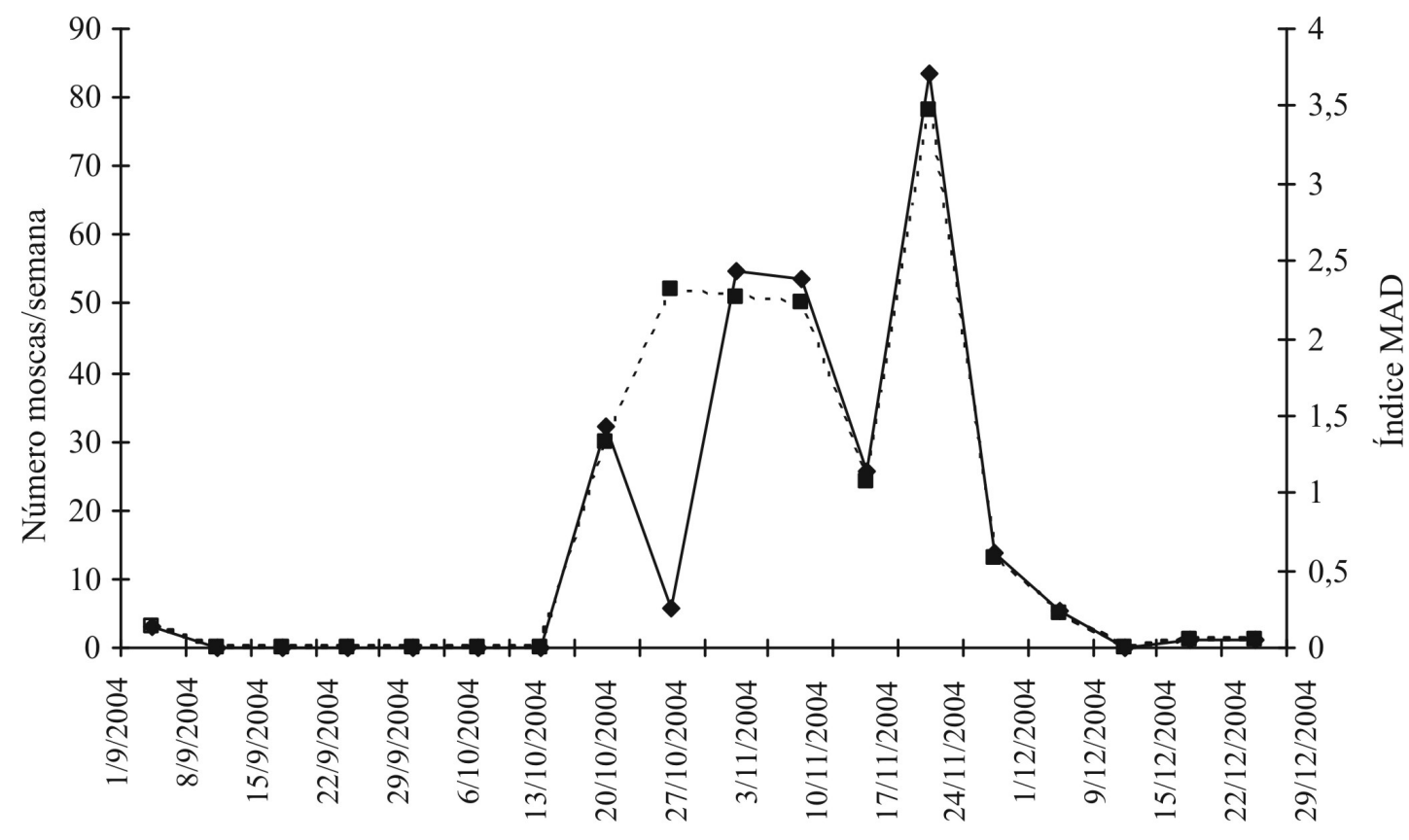

Período observado - Set a Dez/2004

FIGURA 2 - Flutuação populacional de Ceratitis capitata capturadas em armadilhas tipo McPhail. Presidente Prudente-SP. Setembro a dezembro de 2004.



Período observado

… . Índice MAD —— número moscas/armadilha/semana

FIGURA 3 - Flutuação populacional de Ceratitis capitata capturadas em armadilhas tipo McPhail. Presidente Prudente-SP. Janeiro a dezembro de 2006. 
TABELA 1 - Correção linear da temperatura e precipitação e a influência na dinâmica populacional de Ceratitis capitata. Presidente Prudente-SP. 2004/2006.

\begin{tabular}{ccccc}
\hline \multirow{2}{*}{ Período } & $\begin{array}{c}\text { Variável de } \\
\text { infestação }\end{array}$ & $\begin{array}{c}\text { Variável de } \\
\text { clima }\end{array}$ & $\begin{array}{c}\text { Correlação } \\
\text { significativa } \\
*\end{array}$ & $\begin{array}{c}\text { Maior correlação } \\
\mathbf{r}\end{array}$ \\
\hline \multirow{2}{*}{2004 a 2006} & Ceratitis capitata & Temperatura & $0,819 \mathrm{~ns}$ & $-0,044$ \\
& & Precipitação & $0,919 \mathrm{~ns}$ & 0,019 \\
\hline
\end{tabular}

TABELA 2 - Infestação de Tephritoidea em frutos de cultivares de pessegueiros enxertados sobre Okinawa e Umê. Presidente Prudente-SP. 2004.

\begin{tabular}{ccccc}
\hline \multirow{2}{*}{ Cultivares } & \multicolumn{4}{c}{ Porta-enxerto Okinawa } \\
\cline { 2 - 5 } & $\begin{array}{c}\text { núm.médio } \\
\text { frutos }{ }^{1}\end{array}$ & $\begin{array}{c}\% \\
\text { infestação }\end{array}$ & $\begin{array}{c}\text { Peso } \\
\text { médio/fr. }\end{array}$ & $\begin{array}{c}\text { Núm.médio } \\
\text { mosca/fr. }\end{array}$ \\
\hline Tropical & 8,67 & 54,68 & 61,69 & 3,53 \\
Aurora 2 & 1,50 & 100,00 & 81,11 & 2,25 \\
Talismã & 51,67 & 63,62 & 72,75 & 3,31 \\
Dourado 2 & 1,50 & 50,00 & 72,02 & 4,00 \\
Doçura 2 & 8,00 & 71,82 & 72,45 & 4,91 \\
Aurora 1 & 3,00 & 52,38 & 55,09 & 2,81 \\
\hline Média & 13,75 & 55,38 & 68,26 & 2,05 \\
F cultivar & $2,53 \mathrm{~ns}$ & $1,07 \mathrm{~ns}$ & $0,96 \mathrm{~ns}$ & $0,40 \mathrm{~ns}$ \\
CV (\%) & 145,28 & 47,48 & 20,33 & 29,61 \\
\hline & & Porta-enxerto Umê & \\
\hline Tropical & 3,50 & $0,00 \mathrm{c}$ & 87,05 & 0,00 \\
Aurora 2 & 8,67 & $100,00 \mathrm{a}$ & 63,73 & 8,81 \\
Talismã & 13,33 & $61,53 \mathrm{ab}$ & 80,36 & 4,20 \\
Dourado 2 & 18,00 & $77,78 \mathrm{ab}$ & 70,67 & 7,06 \\
Doçura 2 & 8,00 & $46,37 \mathrm{~b}$ & 70,14 & 3,32 \\
Aurora 1 & 4,00 & $82,22 \mathrm{ab}$ & 75,97 & 3,50 \\
\hline Média & 8,50 & 55,75 & 74,66 & 2,22 \\
F cultivar & $0,97 \mathrm{~ns}$ & $9,49 *$ & $0,25 \mathrm{~ns}$ & $3,20 \mathrm{~ns}$ \\
CV $(\%)$ & 84,53 & 25,95 & 33,98 & 23,31 \\
\hline
\end{tabular}


TABELA 3 - Infestação de Tephritoidea em frutos de cultivares de pessegueiros enxertados sobre Okinawa e Umê. Presidente Prudente-SP. 2006.

\begin{tabular}{ccccccc}
\hline & \multicolumn{5}{c}{ Porta-enxerto Okinawa } \\
\cline { 2 - 7 } Tratamentos & $\begin{array}{c}\text { núm.médio } \\
\text { frutos }^{1}\end{array}$ & $\begin{array}{c}\% \\
\text { infestação }^{2}\end{array}$ & $\begin{array}{c}\text { Peso } \\
\text { médio/fr. }\end{array}$ & $\begin{array}{c}\text { Núm.médio } \\
\text { mosca/fr. }\end{array}$ & $\begin{array}{c}\text { \% C.capitatal } \\
\text { Total }\end{array}$ & $\begin{array}{c}\text { \% Neosilba/ } \\
\text { Total }\end{array}$ \\
\hline Tropical & 20,00 & 13,14 & 78,50 & 0,05 & 36,85 & 3,15 \\
Aurora 2 & 19,80 & 32,25 & 65,76 & 1,30 & 88,07 & 11,53 \\
Talismã & 35,60 & 42,35 & 85,04 & 202 & 74,05 & 25,95 \\
Dourado 2 & 36,00 & 37,50 & 87,56 & 1,70 & 91,70 & 8,30 \\
Doçura 2 & 36,40 & 37,15 & 55,58 & 2,00 & 86,88 & 12,50 \\
Aurora 1 & 8,20 & 15,35 & 58,01 & 0,70 & 31,93 & 8,07 \\
\hline Média & 28,44 & 32,47 & 69,28 & 1,63 & 62,54 & 17,38 \\
F cultivar & $2,63 \mathrm{~ns}$ & $1,79 \mathrm{~ns}$ & $2,66 \mathrm{~ns}$ & $1,75 \mathrm{~ns}$ & $1,13 \mathrm{~ns}$ & $1,65 \mathrm{~ns}$ \\
CV (\%) & 40,24 & 40,03 & 22,08 & 18,37 & 35,06 & 49,08 \\
\hline & \multicolumn{5}{c}{ Porta-enxerto Umê } \\
\hline Tropical & 4,60 & 4,76 & 85,14 & 0,20 & 20,00 & 0,00 \\
Aurora 2 & 6,40 & 37,02 & 73,37 & 2,20 & 52,49 & 7,51 \\
Talismã & 52,00 & 56,79 & 101,36 & 4,40 & 83,84 & 15,74 \\
Dourado 2 & 17,75 & 27,35 & 93,25 & 1,30 & 46,38 & 3,60 \\
Doçura 2 & 36,80 & 54,23 & 65,70 & 3,10 & 89,95 & 10,00 \\
Aurora 1 & 15,50 & 25,90 & 69,98 & 1,70 & 72,52 & 2,48 \\
\hline Média & 24,28 & 34,50 & 80,40 & 1,78 & 58,85 & 11,09 \\
F cultivar & $2,32 \mathrm{~ns}$ & $1,41 \mathrm{~ns}$ & $1,76 \mathrm{~ns}$ & $1,78 \mathrm{~ns}$ & $1,44 \mathrm{~ns}$ & 97,01 \\
CV (\%) & 63,91 & 61,56 & 21,20 & 28,61 & 50,98 & $1,65 \mathrm{~ns}$ \\
\hline
\end{tabular}

TABELA 4 - Correlação linear da infestação de moscas-das-frutas nos frutos e características químicas (sólidos solúveis e acidez titulável) em Presidente Prudente-SP. 2004/2006.

\begin{tabular}{|c|c|c|c|c|c|}
\hline Período & Porta-enxerto & $\begin{array}{l}\text { Variável de } \\
\text { infestação }\end{array}$ & $\begin{array}{c}\text { Variável de } \\
\text { característica } \\
\text { químicas dos frutos }\end{array}$ & $\begin{array}{c}\text { Correlação } \\
\text { significativa } \\
*\end{array}$ & $\begin{array}{c}\text { Maior } \\
\text { correlação } \\
\mathbf{r}\end{array}$ \\
\hline \multirow{4}{*}{2006} & \multirow{4}{*}{ Okinawa } & $\begin{array}{l}\text { Núm. Médio } \\
\text { moscas }^{1}\end{array}$ & Sólidos solúveis & $0,076 \mathrm{~ns}$ & $-0,289$ \\
\hline & & & Acidez titulável & $0,156 \mathrm{~ns}$ & 0,206 \\
\hline & & & Sólidos solúveis & $0,117 \mathrm{~ns}$ & $-0,242$ \\
\hline & & & Acidez titulável & $0,064 \mathrm{~ns}$ & 0,307 \\
\hline \multirow{5}{*}{2006} & \multirow{5}{*}{ Umê } & $\begin{array}{l}\text { Núm. Médio } \\
\text { moscas }^{1}\end{array}$ & Sólidos solúveis & $0,329 \mathrm{~ns}$ & $-0,129$ \\
\hline & & & Acidez titulável & $0,459 \mathrm{~ns}$ & $-0,031$ \\
\hline & & & Sólidos solúveis & $0,286 \mathrm{~ns}$ & $-0,165$ \\
\hline & & \% infestação ${ }^{2}$ & & & \\
\hline & & & Acidez titulável & $0,292 \mathrm{~ns}$ & 0,16 \\
\hline
\end{tabular}




\section{CONCLUSÃO}

Ceratitis capitata foi predominante nas cultivares de pessegueiros sob dois porta-enxertos na região oeste do Estado de São Paulo, não tendo sido observada correlação significativa entre a população de moscas-das-frutas e as variáveis: temperatura, precipitação, sólidos solúveis e acidez titulável.

\section{AGRADECIMENTOS}

Ao colega Dr. Valmir A. da Costa, pela identificação dos parasitoides, e ao Dr. Miguel Francisco Souza Filho, pelo auxílio na identificação de espécies de Anastrepha.

\section{REFERÊNCIAS}

AGUIAR-MENEZES, E. L.; MENEZES, E. B. Flutuação populacional moscas-das-frutas e sua relação com a disponibilidade hospedeira em ItaguaíRJ. Anais da Sociedade Entomológica do Brasil, Londrina, v.25, n.2, p.223-232, 1996.

COSTA, V. A.; ARAÚJO, E. L. de; GUIMARÃES, J. A.; NASCIMENTO, A. S.; LASALLE, J. Redescoberta de Tetrastichus giffardianus (Hymenoptera: Eulophidae) após 60 anos da sua introdução no Brasil. Arquivos do Instituto Biológico, São Paulo, v.72, n.4, p.539-541, 2005.

FERRARA, F. A. A.; AGUIAR-MENEZES, E. L.; URAMOTO, K.; MARCO JUNIOR, P. D.; SOUZA, S.A. S.; CASSINO, P. C. R. Análise faunística de populações de moscas-das-frutas (Diptera: Tephritidae) da região noroeste do Estado do Rio de Janeiro. In: CONGRESSO BRASILEIRO DE ENTOMOLOGIA, 20., 2004, Gramado. Anais... Gramado SEB, 2004. p.658.

GARCIA, F. R. M.; CAMPOS, J. V.; CORSEUIL, E. Análise faunística de sp moscas-das-frutas (Diptera: Tephritidae) na região oeste de Santa Catarina. Londrina, Neotropical Entomology, Londrina v.32, n.3, p.421-426, 2003a.

GARCIA, F. R. M.; CAMPOS, J. V.; CORSEUIL, E. Flutuação populacional de Anastrepha fraterculus (Wiedemann, 1830) (Diptera: Tephritidae) na região oeste de Santa Catarina, Brasil. Revista Brasileira de Entomologia, São Paulo, v.47, n.3, p.180-185, 2003b.
MALAVASI, A.; MORGANTE, J. S.; ZUCCHI, R. A. Biologia de moscas-das-frutas (Diptera: Tephritidae) I. Lista de hospedeiros e ocorrência. Revista Brasileira de Biologia, Rio de Janeiro, v.40, n.1, p.9-16, 1980

MALAVASI, A.; ZUCCHI, R. A.; SUGAYAMA, R. L. Biogeografia. In: MALAVASI, A.; ZUCCHI, R. A. (Ed.). Moscas-das-frutas de importância econômica no Brasil: conhecimento básico e aplicado. Ribeirão Preto: Holos, 2000. p.93-98.

MARTINS, D. S. Manejo integrado de moscas-dasfrutas. In: ZAMBOLIM, L.(Ed). Manejo integrado de fruteiras tropicais: doenças e pragas. Viçosa: UFV, 2002. p.615-647.

MONTES, S.M.N.M.; BOLIANI, A.C.; RAGA, A.; SANTOS, P.C.; CORREAA, L.S.; FERRARI, J.T. Características produtivas, físicas e químicas de frutos de cultivares de pessegueiros sobre dois portaenxertos no oeste do Estado de Sâo Paulo. Revista Brasileira de Fruticultura, Jaboticabal, v. 30, n.4, p. 1065-1070, 2008.

NASCIMENTO, A. S.; CARVALHO, R. S. Manejo Integrado de Moscas-das-frutas. In: MALAVASI, A.; ZUCCHI, R. A. (Ed.). Moscas-das-frutas de importância econômica no Brasil : conhecimento básico e aplicado. Ribeirão Preto: Holos, 2000. p.169-173.

PARRA, J. R. P.; ZUCCHI, R. A.; SILVEIRANETO, S. Flutuação populacional e atividade de voo da mosca-do-mediterrâneo em cafeeiros Mundo Novo. Pesquisa Agropecuária Brasileira, Brasília, v.17, n.7, p.985-992, 1982.

PEREIRA, F.M.; NACHTIGAL, J.C.; ROBERTO, S.R. Tecnologia para a cultura do pessegueiro em regiões tropicais e subtropicais. Jaboticabal: FUNEP, 2002. 61p.

PUZZI, D.; ORLANDO, A. Estudos sobre a ecologia das "moscas-das-frutas"(Trypetidae) no Estado de São Paulo, visando ao controle racional da praga. Arquivos do Instituto Biológico, São Paulo, v.32, n.1, p.7-22, 1965.

RAGA, A.; PRESTES, D.A.O.; SOUZA FILHO, M.F.; SATO, M.F.; SILOTO, R.C.; ZUCCHI, R.A. Occurrence of fruit flies in coffee varieties in the State of São Paulo, Brazil. Boletin Sanidad Vegetal y Plagas, Madrid, v. 28, p. 519-524, 2002. 
SALLES, L. A. B. Principais pragas e seu controle. In: MEDEIROS, C. A.; RASEIRA, M. C. B. A cultura do pessegueiro. Pelotas: Embrapa Clima Temperado, 1998. p.205-239.

SILVA, F. F. da; MEIRELLES, R N.; SOGLIO, F. K. D.; REDAELLI, L. R. Influência de variáveis climáticas na ocorrência de moscas-das-frutas (Diptera:Tephritidae) em pomares de citros, na região do Vale do Rio Caí, Rio Grande do Sul. In: CONGRESSO BRASILEIRO DE ENTOMOLOGIA, 20., 2004, Gramado. Anais... Gramado: SEB, 2004. p.652.

SOUZA FILHO, M. F. Biodiversidade de moscasdas-frutas (Diptera: Tephritidae) e seus parasitoides (Hymenoptera) em plantas hospedeiras no Estado de São Paulo. Piracicaba: 1999. 174 f. Dissertação (Mestrado em Entomologia) - Escola Superior de Agricultura “Luiz de Queiroz", Universidade de São Paulo, Piracicaba, 1999.

SOUZA FILHO, M. F. Infestação de moscas-dasfrutas (Diptera: Tephritidae e Lonchaeidae) relacionada à fenologia da goiabeira (Psidium guajava L.), nespereira (Eriobotrya japonica Lindl.) e do pessegueiro (Prunus persica Batsch). 2006. $125 \mathrm{f}$. Tese (Doutorado em Agronomia - Entomologia) Escola Superior de Agricultura "Luiz de Queiroz", Universidade de São Paulo. Piracicaba, 2006.
SOUZA FILHO, M. F.; RAGA, A.; ZUCCHI, R. A. Moscas-das-frutas nos estados brasileiros: São Paulo. In: MALAVASI, A.; ZUCCHI, R. A. (Ed.). Moscas-das-frutas de importância econômica no Brasil: conhecimento básico e aplicado. Ribeirão Preto: Holos, 2000. p. 277-283.

SOUZA-FILHO, M.F.; RAGA, A.; AZEVEDOFILHO, J.A.; STRIKIS, P.C.; GUIMARÃES, J.A.; ZUCCHI, R.A. Diversity and seasonality of fruit flies (Diptera: Tephriitdae and Lonchaeidae) and their parasitoids (Hymenoptera: Braconidae and Figitidae) in orchards of guava, loquat and peach. Brazilian Journal of Biology, São Carlos, v. 69, n.1, p. 31-40, 2009.

UCHÔA, M. A.; OLIVEIRA, I. de; MOLINA, R. M. S.; ZUCCHI, R. A. Species diversity of frugivorous flies (Diptera: Tephritidae) from hosts in the cerrado of the State of Mato Grosso do Sul, Brazil. Neotropical Entomology, Londrina, v.31, n.4, p.515-524, 2002.

ZUCCHI, R. A. Taxonomia. In: MALAVASI, A.; ZUCCHI, R. A. (Ed.). Moscas-das-frutas de importância econômica no Brasil: conhecimento básico e aplicado. Ribeirão Preto: Holos, 2000a. p.13-24.

ZUCCHI, R. A. Mosca-do-mediterrâneo, Ceratitis capitata (Diptera:Tephritidae). In: VILELA, E. E.; ZUCCHI, R. A.; CANTOR, F. (Ed.). Histórico e impacto das pragas introduzidas no Brasil. Ribeirão Preto: Holos, 2000b. cap.1, p.15-22. 